\title{
Influence of Pre-Stressing on Tieback Retaining Wall for Sandy Soils Excavations
}

\author{
Anthonius Steven Sutanto ${ }^{*}$, Paulus Pramono Rahardjo, Aswin Lim \\ Department of Civil Engineering, Universitas Katolik Parahyangan, Bandung, INDONESIA \\ Jalan Ciumbuleuit No. 94 Bandung \\ *Corresponding authors: steven.sutanto@outlook.com
}

SUBMITTED 26 November 2020 REVISED 27 Februari 2021 ACCEPTED 23 April 2021

\begin{abstract}
Pre-stressed ground anchor systems or tieback systems are commonly used at wide and irregular-shaped excavations, with the advantage of lower cost and ease of construction compared to the braced excavations, but they come with the drawback on permits for excavations near buildings and tunnels. Research on tieback systems in sands was generally conducted. However, the studies on the correlation between the retaining wall deflection and pre-stress force are few. The objectives of this paper are to study the influence of pre-stress force, depth of excavation, wall embedment length, and soil shear strength that is represented by soil friction angle on the deflection and soil pressure acting on the retaining wall. The parametric study was conducted on an excavation in sand using the finite element method with the Hardening soil model. The results showed that a $50 \mathrm{kN} / \mathrm{m}$ increase in pre-stress force reduced the wall deflection on top of the wall by $0.005-0.083 \%$ of excavation depth. However, the pre-stressing influence in reducing wall deflection at excavations became less significant along with the sand density increase due to higher friction angle contribution to excavation stability. Moreover, the pre-stress force needed for stabilization of the wall with long embedment length is smaller than those on the wall with shorter embedment length, since the embedment length increase of 0.25 times of excavation depth reduces wall top deflection by $0.002-0.095 \%$ of excavation depth. Also, the increase of soil density reduces the need for wall embedment length, so at dense sand, the embedment length of 0.5 times of excavation depth is sufficient to support the excavation.
\end{abstract}

KEYWORDS Excavation; Sandy soil; Ground anchor; Pre-stress; Tieback system

(c) The Author(s) 2021. This article is distributed under a Creative Commons Attribution-ShareAlike 4.0 International license.

\section{INTRODUCTION}

Deep excavations in cohesionless soil possess challenges in geoengineering practice. Despite the advanced construction techniques and equipment, there is no room for small errors to alleviate risks in the construction of critical underground structures (Birid et al., 2020). However, underground construction is unavoidable in cities with population growth and urban land scarcity. Therefore, retaining structure designs have to satisfy the requirements of all stakeholders involved in excavation projects (Fuentes et al., 2018).

An excavation stabilization method that is the focus of this study is the pre-stressed ground anchor systems or commonly known as tieback systems. Tieback systems are often used to stabilize wide and irregular-shaped excavations.
At those excavations, tieback systems cost less and are easier to construct than braced excavations. However, tieback systems have problems with permits at excavations with neighboring buildings and tunnels. To assess a deep excavation design, a numerical analysis is performed. The reductions in wall displacement, ground settlement, and the axial load capacity of the ground anchor are considered in determining pre-stress levels. A design that meets maximum wall displacement, ground settlement, and the axial load capacity of the ground anchor can be achieved through soil constitutive models and soil-structure interactions in finite element analysis (St. Clair, 2017).

This study aims to investigate the influence of pre-stress force $(F)$, depth of excavation $\left(H_{e}\right)$, wall 
embedment length $\left(H_{p}\right)$, and soil density that is represented by soil friction angle $\left(\phi^{\prime}\right)$ on deflection and pressure working on retaining wall. Moreover, the correlation between four parameters and deflection and pressure of soil on the wall is plotted in charts.

There are several studies on excavations in sandy soils by Hsiung et al. (2016), Khoiri and Ou (2013), and Elbaz et al. (2018), but those studies have not yet studied the effect of pre-stressing on retaining wall deflection on tieback excavations parametrically. The effect of pre-stress force on soil anchor in sandy soil excavation was discussed by Nikolinakou et al. (2011) and Elhakim and Tahsin (2011). However, these studies have not produced a product in the form of curves for the relationship between wall deflection and the amount of pre-stress force applied.

\section{LITERATURE REVIEW}

Elhakim and Tahsin (2011) conducted a parametric study on the effect of post-tensioning on tieback diaphragm wall excavation in sand using the finite element method. The variations of parameters consisted of pre-stress force ratio, sand density, and diaphragm wall thickness. The wall deflections showed that pre-stress force influenced in reducing wall deflection and its influence tends to be more significant in loose sand with lower density than in sand with higher density. Besides, the reduction in wall deflection from the pre-stress ratio of $60 \%$ to $120 \%$ was smaller than the reduction from $0 \%$ to $60 \%$. The results showed that applying pre-stressing from no pre-stress condition has a greater influence in reducing wall deflection than applying from existing pre-stress force condition.

A VZB project excavation near Lehrter-Bahnhof was studied by Nikolinakou et al. (2011), where the excavation was constructed in Berlin Sand. The study used the MIT-S1 model and Hardening Soil model to perform a numerical analysis, and a comparison with inclinometer measurement was also conducted in the study. The computed deflection and ground settlement matched closely with the measurements, with slight differences. The wall toe from the Hardening Soil model before pre-stressing had a displacement of almost $1 \mathrm{~cm}$, while the measured deflection at the wall toe did not show any noticeable displacements. Also, the computed ground settlement at top of the wall deflected towards the top, while the measured settlement had only raised slightly.

A braced excavation in sandy soil in Kaoshiung was studied by Hsiung et al. (2016) to predict wall displacements. In addition, the plane strain ratio for excavations in loose to medium dense sands was determined in the study. The study utilized three-dimensional finite element analysis and then the analysis results compared to the measured results. The variation in soil moduli from empirical correlations from SPT test and modulus from DMT test were included in the analysis. The wall deflection from analysis using correlations from SPT test is closer to measurements compared to the analysis using modulus from DMT test. Also, a plane strain ratio chart for excavations in loose to medium dense sands was developed from the analysis.

Elbaz et al. (2018) studied the performance of a $16 \mathrm{~m}$ braced excavation in sand-covered karst in Metro Line no. 9, Guangzhou, China by comparing the maximum wall deflection empirical formula, previous studies, and inclinometer measurement. The wall deflection measurement results varied from $0.08 \%$ to $0.13 \%$ of excavation depth, which matched the empirical formula and previous studies.

As per the above-mentioned studies, finite element analysis is widely used and accepted to simulate deep excavation supported by lateral supports with satisfying results.

\section{RESEARCH METHOD}

\subsection{Excavation Model Geometry}

This research is conducted by the means of numerical analysis with variations on parameters, namely parametric study. As shown in Figure 1, the parametric study uses an ideal two-dimensional excavation model with its 
dimensions. Half of the excavation width is assumed $50 \mathrm{~m}$. This excavation model is supported by a concrete diaphragm wall with 0.6 $\mathrm{m}$ in thickness and ground anchor with an unbonded length of $10 \mathrm{~m}$ and bonded length of $10 \mathrm{~m}$. The ground anchor is constructed at $2 \mathrm{~m}$ depth from the soil surface with an inclination of $30^{\circ}$ from the horizontal line. The retained side width, $B_{r}$, at $5 \mathrm{~m}$ and $8 \mathrm{~m}$ excavation depth is 40 $\mathrm{m}$, while at $12 \mathrm{~m}$ excavation depth, $B_{r}$ is $50 \mathrm{~m}$.

\subsection{Parameter Variations}

In this study, there are 4 parameter variations, namely excavation depth $\left(H_{e}\right)$, wall embedment length $\left(H_{p}\right)$, friction angle of sand $(\phi)$, and prestress force $(F)$. Excavation depth variations used in this study were $5 \mathrm{~m}, 8 \mathrm{~m}$, and $12 \mathrm{~m}$. Variations of wall embedment length, $H_{p}$, were $0.5 H_{e}, 0.75 H_{e}$, and $1.0 H_{e}$. Soil properties used for this study are determined using assumption; the soil is assumed as homogenous sandy soils with $\phi$ variations of $28^{\circ}, 33^{\circ}$, and $38^{\circ}$, which represent loose sand, medium sand, and dense sand respectively. Variations of F used are $0 \mathrm{kN}, 50 \mathrm{kN}$, $100 \mathrm{kN}, 300 \mathrm{kN}$, and $600 \mathrm{kN}$. Therefore, there are
135 properties variations for this study. All properties variations are listed in Table 1.

\subsection{Hardening Soil Model}

Based on a study conducted by Lim et al. (2010), Wang et al. (2019), and Teo and Wong (2012), the Hardening Soil model is able to compute wall deflections close to the actual wall deflections measured at the last stage of soil excavation. Those three studies proved that retaining wall deflection from Hardening Soil model analysis is close to deflection from inclinometer measurement. A study conducted by Han et al. (2017) found that Hardening Soil and MohrCoulomb are similar to actual measurement, but the Mohr-Coulomb model is more conservative in soil settlement calculation on the excavation.

The Hardening Soil model simulates the behavior of various types of soil using a hyperbolic curve approach and three soil moduli namely $E_{50}, E_{\text {oed }}$, and $E_{u r} . E_{50}$ is soil elastic modulus at primary deviatoric loading condition, $E_{\text {oed }}$ soil modulus at primary consolidation, and $E_{u r}$ soil modulus at unloading/reloading condition.

$50 \mathrm{~m}$

$\mathrm{Br}_{\mathrm{r}}$

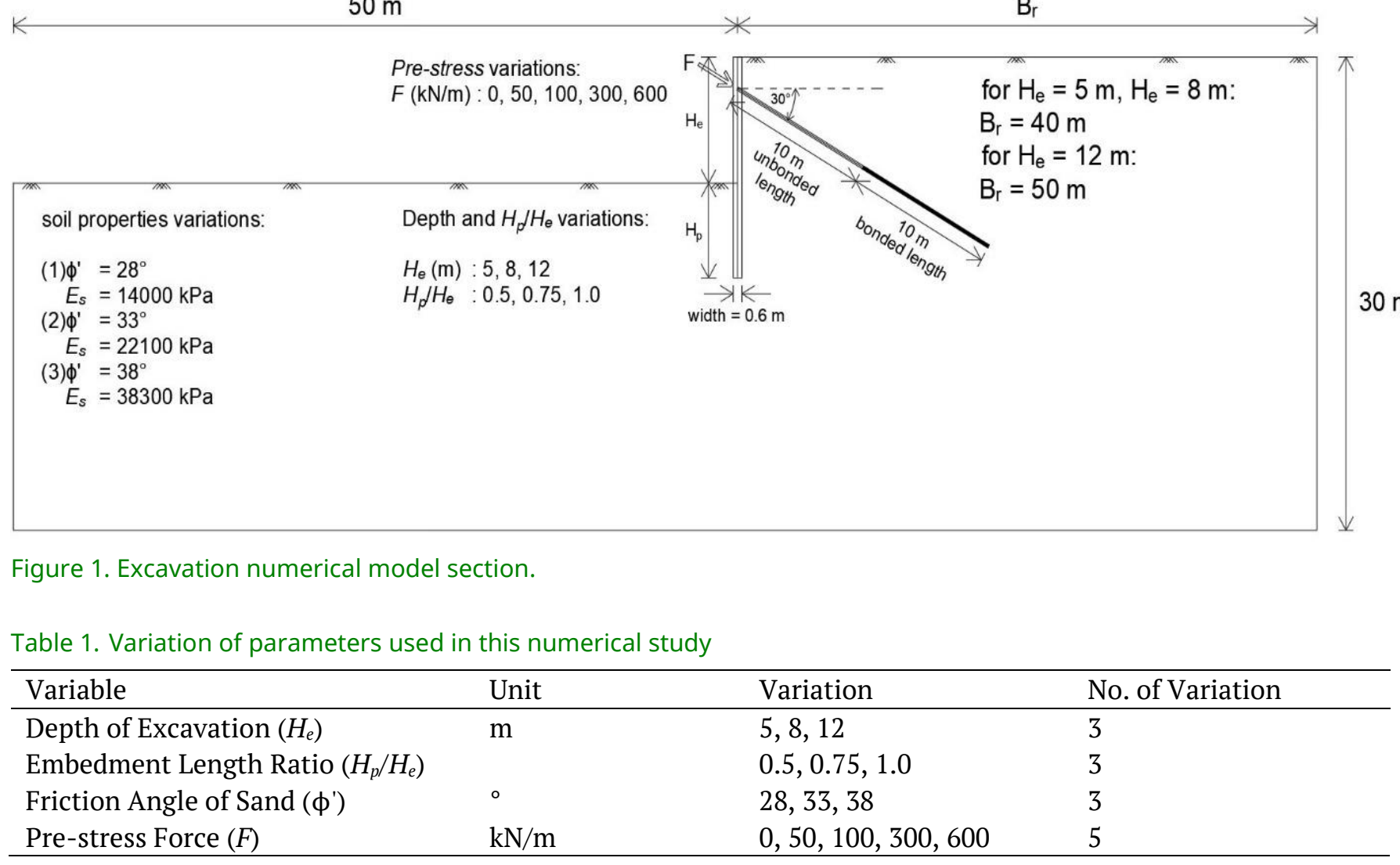


In the Hardening Soil model, soil stiffness decreased when main deviatoric loading was applied, and plastic strain occurred simultaneously. At drained triaxial test, relations of vertical strain, $\varepsilon_{1}$, and deviatoric stress, $q$, can be approximated by a hyperbolic curve (Kondner and Zelasko, 1963; Duncan and Chang, 1970). A hyperbolic curve equation for the standard drained triaxial test is written as follows:

$\varepsilon_{1}=\frac{1}{E_{i}} \frac{q}{1-q / q_{a}}$ for $q<q_{f}$

where $q_{a}$ is asymptotic shear strength and $E_{i}$ is initial stiffness. The relationship between $E_{i}$ and $E_{50}$ is defined in Equation (2), where $R_{f}$ is failure ratio.

$E_{i}=\frac{2 E_{50}}{2-R_{f}}$

$E_{50}$ is the stiffness modulus which depends on the confining stress for main loading and can be formulated in Equation (3),

$E_{50}=E_{50}^{r e f}\left(\frac{c \cos \phi-\sigma_{3}^{\prime} \sin \phi}{c \cos \phi+p^{r e f} \sin \phi}\right)^{m}$

where $c$ is soil cohesion, $\phi$ sand friction angle, $\sigma_{3}^{\prime}$ effective confining stress and $E_{50}^{\text {ref }}$ stiffness modulus at reference stress $\left(p^{\text {ref }}\right)$ of $100 \mathrm{kPa}$. The actual stiffness depends on the confining pressure $\sigma_{3}^{\prime}$ in triaxial test, which is negative if $\sigma^{\prime}{ }_{3}$ is compressive. The power $m$ denotes stress dependency. To simulate compressive behavior in soft clay, $m$ equals 1 . The $m$ in Norwegian sands and silts is 0.5 (Janbu, 1963) and $m$ in different soil types is in a range from 0.5 to 1 (von Soos, 1990).

Ultimate deviatoric stresses, $q_{f}$, and $q_{a}$, in Equation (1) described as follows:

$q_{f}=\left(c \cot \phi-\sigma_{3}^{\prime}\right) \frac{2 \sin \phi}{1-\sin \phi}$

$q_{a}=\frac{q_{f}}{R_{f}}$

Equation (4) is derived from Mohr-Coulomb failure criteria using soil cohesion, $c$, and soil friction angle, $\phi$. After reaching $q=q_{\text {f }}$, the soil undergoes complete plastic failure as in the Mohr-Coulomb model. In Equation (5), $q_{f}-q_{a}$ ratio is called the failure ratio, $R_{f}$, which is less than 1. In PLAXIS, $R_{f}=0.9$ is used by default.

The hyperbolic stress-strain relationship in the Hardening Soil is illustrated in the curve in Figure 2. The deviatoric stress increases in a hyperbolic manner from zero to ultimate deviatoric stress $q_{f}$ at axial strain increase. The Hardening Soil model assumes that the deviatoric stress fails at $q_{f}$, but if the curve is plotted above $q_{f}$ line, the peak of the curve reaches $q_{a}$, the failure deviatoric stress at asymptote line.

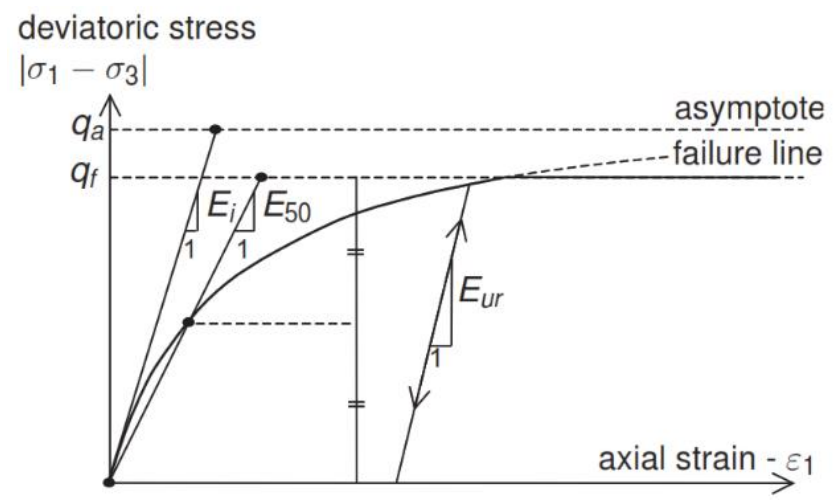

Figure 2. Standard drained triaxial test stress-strain curve (Schanz et al., 1999)

For unloading and reloading, $E_{u r}$ is used, as in Equation (6), where $E_{u r}^{\text {ref }}$ is reference Young modulus for unloading and reloading $\left(p^{\text {ref }}\right)$. In practice, $E_{u r}^{r e f}$ equals to $3 E_{50}^{\text {ref }}$ (Schanz et al., 1999).

$E_{u r}=E_{u r}^{r e f}\left(\frac{\mathrm{c} \cos \phi-\sigma_{3}^{\prime} \sin \phi}{\mathrm{c} \cos \phi+p^{r e f} \sin \phi}\right)^{m}$

The calculation of unloading and reloading shear modulus, $G_{u r}$, uses Hooke's law of isotropic elasticity conversion between $E$ and $G$, which can be written as Equation (7), where $v_{u r}$ is the Poisson's ratio at unloading and reloading. The oedometer modulus, $E_{\text {oed }}$, is defined in Equation (8), where $K_{0}, N C$ is lateral earth pressure coefficient in normally consolidated stress state.

$$
\begin{aligned}
& G_{u r}=\frac{1}{2\left(1+v_{u r}\right)} E_{u r}, p^{r e f}=100 \mathrm{kPa} \\
& E_{\text {oed }}=E_{\text {oed }}^{r e f}\left(\frac{c \cos \phi-\frac{\sigma_{3}^{\prime}}{K_{0}, N C} \sin \phi}{c \cos \phi+p^{r e f} \sin \phi}\right)^{m}
\end{aligned}
$$




\subsection{Soil Parameters Setting}

Soil parameters are chosen according to the empirical correlations of soil relative density $\left(D_{r}\right)$, effective friction angle of soil $\left(\phi^{\prime}\right)$, and soil unit weight $\left(\gamma_{s}\right)$ to corrected SPT values and soil description. Soil parameter variations, namely $\phi^{\prime}$, SPT values, $\gamma_{s}, E_{50}, E_{o e d}$, and $E_{u r}$, are described in Table 2. Elastic modulus of soil at $50 \%$ of maximum stress, $E_{50}$, for sandy soils, is taken equal to the elastic modulus of sands $\left(E_{s}\right) . E_{u r}$ used is equal to $3 E_{50}$, and $E_{\text {oed }}$ is equal to $E_{u r}$. $\phi^{\prime}$ used in this study is based on a correlation between SPT values and $\phi$ ' in Equation (9) by Hatanaka and Uchida (1996), and Equation (10) by Chen (2004), where $N$ is SPT N-value, and $\left(N_{1}\right)_{60}$ is SPT $\mathrm{N}$-value normalized at effective overburden pressure of $100 \mathrm{kPa}$ and free-fall hammer energy efficiency of $60 \%$. Based on the correlation in Table 3 (Terzaghi and Peck, 1948; Gibbs and Holtz, 1957), SPT value for loose sand is 4 with $\phi^{\prime}$ of $28^{\circ}$, SPT value for medium sand is 20 with $\phi^{\prime}$ of $33^{\circ}$, and SPT value for dense sand is 35 with $\phi^{\prime}$ of $38^{\circ}$. The dilation angle is not considered in this study.

$\phi^{\prime} \approx \sqrt{20 N}+18$ $\phi^{\prime}=27.5+9.2 \log _{10}\left[\left(N_{1}\right)_{60}\right]$

The retaining wall used in this analysis is a concrete diaphragm wall with its elastic modulus $\left(E_{c}\right)$ of $20000 \mathrm{MPa}$ or $2 \times 10^{7} \mathrm{kPa}$ and a Poisson's ratio (v) of 0.15 . The equivalent wall thickness, $d_{e q}$, is calculated automatically in the software using Equation (11). The $d_{e q}$ of the wall used is 0.6 m. Thus, the wall stiffness properties, $E_{c} A_{w}$ and $E_{c} I_{w}$, are $12 \times 10^{6} \mathrm{kN} / \mathrm{m}$ and $360000 \mathrm{kNm}^{2} / \mathrm{m}$ respectively for all variations of the analyzed model.

$d_{e q}=\sqrt{12 \frac{E_{c} I_{w}}{E_{c} A_{w}}}$

Wall element weight $\left(w_{\text {plate }}\right)$ at the numerical model is calculated by subtracting the average unit weight of soil ( $\left.\gamma_{s_{\text {_ave }}}\right)$ from the unit weight of wall structure $\left(\gamma_{\text {wall }}\right)$, as written in Equation (12) and $w_{\text {plate }}$ values are tabulated in Table 4 . The average unit weight of soils is obtained from averaging an unsaturated unit weight of soils $\left(\gamma_{s_{\text {_unsat }}}\right)$ and saturated unit weight of soils $\left(\gamma_{s_{-} \text {sat }}\right)$.

$w_{\text {plate }}=\left(\gamma_{\text {wall }}-\gamma_{s_{-} \text {ave }}\right) \cdot d_{e q}$

Table 2. Soil parameter variations used in this study

\begin{tabular}{lllllll}
\hline$\phi^{\prime}\left(^{\circ}\right)$ & $\mathrm{N}-\mathrm{SPT}$ & $\gamma_{\mathrm{s} \_ \text {unsat }}\left(\mathrm{kN} / \mathrm{m}^{3}\right)$ & $\gamma_{\mathrm{s} \_ \text {sat }}\left(\mathrm{kN} / \mathrm{m}^{3}\right)$ & $E_{50}(\mathrm{MPa})$ & $E_{\text {oed }}(\mathrm{MPa})$ & $E_{\text {ur }}(\mathrm{MPa})$ \\
\hline 28 & 4 & 14 & 16 & 14.0 & 14.0 & 42.0 \\
33 & 20 & 15 & 17 & 22.1 & 22.1 & 66.3 \\
38 & 35 & 16 & 18 & 38.3 & 38.3 & 114.9 \\
\hline
\end{tabular}

Table 3. $D_{r}, \phi$, and $\gamma_{s}$ empirical values of coarse-grained soil based on corrected SPT values (Terzaghi and Peck, 1948) (Gibbs and Holtz, 1957)

\begin{tabular}{llllll}
\hline Description & Very Loose & Loose & Medium & Dense & Very Dense \\
\hline N-SPT Value & $0-4$ & $4-10$ & $10-30$ & $30-50$ & $>50$ \\
Relative density, $D_{r}(\%)$ & $0-15$ & $15-35$ & $35-65$ & $65-85$ & $85-100$ \\
Friction angle $\left(\phi,^{\circ}\right)$ & $<28$ & $28-30$ & $30-36$ & $36-41$ & $>41$ \\
Soil unit weight $\left(\gamma_{s}\right)$ & $11.0-15.7$ & $14.1-18.1$ & $17.4-20.4$ & $17.3-22.0$ & $20.4-23.6$ \\
\hline
\end{tabular}

Table 4. Wall section properties used in the analysis

\begin{tabular}{|c|c|c|c|c|}
\hline$\gamma_{\text {s_unsat }}\left(\mathrm{kN} / \mathrm{m}^{3}\right)$ & $\gamma_{s_{-} \text {sat }}\left(\mathrm{kN} / \mathrm{m}^{3}\right)$ & $\gamma_{\mathrm{s}_{-} \text {ave }}\left(\mathrm{kN} / \mathrm{m}^{3}\right)$ & $w_{\text {plate }}(\mathrm{kN} / \mathrm{m} / \mathrm{m})$ & $v$ \\
\hline 14 & 16 & 15 & 5.4 & 0.15 \\
\hline 15 & 17 & 16 & 4.8 & 0.15 \\
\hline 16 & 18 & 17 & 4.2 & 0.15 \\
\hline
\end{tabular}


Ground anchor head is installed at $2 \mathrm{~m}$ below ground surface elevation. The ground anchor has pre-stressing strands with $80 \mathrm{~mm}$ in diameter, with its anchor bonded length diameter $\left(d_{b}\right)$ of $200 \mathrm{~mm}$. The horizontal spacing is $3 \mathrm{~m}$.

The bonded length equivalent elastic modulus $\left(E_{\text {eq }}\right)$ is computed in Equation (13), while the equivalent volume weight of ground anchor tendon $\left(\gamma_{\mathrm{eq}}\right)$ formula is written in Equation (14), where $A$ is the gross area of ground anchor section, $A_{g}$ the grout area, and $A_{n}$ the tendon area.

$E_{e q}=E_{n}\left(\frac{A_{n}}{A}\right)+E_{g}\left(\frac{A_{g}}{A}\right)$

$\gamma_{\mathrm{eq}}=\gamma_{\mathrm{n}}\left(\frac{A_{n}}{A}\right)+\gamma_{\mathrm{g}}\left(\frac{A_{g}}{A}\right)$

Equation (15) is used to calculate bonded length friction resistance $\left(T_{u}\right)$, where $\tau_{u l t}$ is ultimate friction between anchor bonded length and soil, and $L_{a}$ length of bonded length. The $\tau_{\text {ult }}$ values used in this study are listed in Table 5. The $T_{u}$ value is divided by $L_{a}$ to be inputted in the analysis as $T_{\text {top, } \max }$ and $T_{b o t, \max }$ parameters as shown in Equation (16).

$T_{u}=\pi d_{b} L_{a} \tau_{\mathrm{ult}}$

$T_{t o p, \max }=T_{b o t, \max }=T_{u} / L_{a}$

\subsection{Interface Characteristic}

Interface characteristic is determined as strength value of interface from materials and soil, denoted in $R_{\text {inter }}$. $R_{\text {inter }}$ value of 1.0 signifies that interface characteristic is not reduced.
In general, the interface is weaker and more flexible than the adjacent soil, therefore $R_{\text {inter }}$ should be less than 1 . It is suggested that the interface constant for concrete and sand is 0.8 (Gouw, 2014). Hence, the value is selected for this analysis.

\subsection{Retaining Wall and Strut}

The retaining wall is modeled as plate material with its elastic modulus of $20000 \mathrm{MPa}$, equal to 2 $\times 10^{7} \mathrm{kPa}$. The interface is applied on both sides of the retaining wall. The ground anchor strands are assigned as a node-to-node anchor with its stiffness $(E A)$ of $985203 \mathrm{kN}$ and $3 \mathrm{~m}$ spacing. The ground anchor bonded length is modeled as an embedded pile row.

\subsection{Meshing and Groundwater Table}

The numerical model of the excavation is divided into medium-sized meshes for analysis by PLAXIS software as shown in Figure 3. The meshing process results in 835-851 elements and 6929-7073 nodes for $5 \mathrm{~m}$ excavation, 743-781 elements and 6213-6533 nodes for $8 \mathrm{~m}$ excavation, and 663-792 elements and 55816639 nodes for $12 \mathrm{~m}$ excavation. The number of elements and nodes for each excavation depth and wall embedment length are described in Table 6. The excavation model is not restrained on the left, right, and bottom since the excavation model can deform on all sides. The groundwater table is not shown because groundwater table change is not considered in this study.

Table 5. Ground anchor bonded length shear strength parameter

\begin{tabular}{|c|c|c|c|c|c|}
\hline Parameter & Symbol & Value & & & Unit \\
\hline Density & - & Loose & Medium & Dense & - \\
\hline Bonded length - soil ultimate friction & tult & 100 & 230 & 380 & $\mathrm{kN} / \mathrm{m}^{2}$ \\
\hline Maximum friction resistance at the top of bonded length & Ttop, max & 62.83 & 144.5 & 238.8 & $\mathrm{kN} / \mathrm{m}$ \\
\hline Maximum friction resistance at the bottom of bonded length & Tbot, max & 62.83 & 144.5 & 238.8 & $\mathrm{kN} / \mathrm{m}$ \\
\hline
\end{tabular}


Table 6. The number of elements and nodes for each excavation depth and embedment length.

\begin{tabular}{|c|c|c|c|c|c|c|c|}
\hline \multicolumn{4}{|c|}{ Elements } & \multicolumn{4}{|c|}{ Nodes } \\
\hline \multirow{2}{*}{$\begin{array}{l}\mathrm{He}_{\mathrm{e}} \\
(\mathrm{m})\end{array}$} & \multicolumn{3}{|c|}{$\mathrm{H}_{\mathrm{p}} / \mathrm{H}_{\mathrm{e}}$} & \multirow{2}{*}{$\begin{array}{l}\mathrm{He}_{\mathrm{e}} \\
(\mathrm{m})\end{array}$} & \multicolumn{3}{|l|}{$\mathrm{H}_{\mathrm{p}} / \mathrm{H}_{\mathrm{e}}$} \\
\hline & 0.5 & 0.75 & 1.0 & & 0.5 & 0.75 & 1.0 \\
\hline 5 & 835 & 835 & 851 & 5 & 6929 & 6937 & 7073 \\
\hline 8 & 763 & 743 & 781 & 8 & 6365 & 6213 & 6533 \\
\hline 12 & 770 & 792 & 663 & 12 & 6447 & 6639 & 5581 \\
\hline
\end{tabular}

\section{$3.8 \mathrm{~K}_{0}$ Procedure}

The analysis was carried out using $K_{0}$ procedure which can be applied to soil and groundwater level without inclination. The coefficient of lateral earth pressure, $K_{0}$, is computed in Equation (17) (Jaky, 1944). $K_{0}$ for overconsolidated soil is calculated in Equation (18) (Mayne and Kulhawy, 1982), where $K_{0, \text { oc }}$ is lateral earth pressure coefficient for overconsolidated soil and $K_{0, N_{N C}}$ is lateral earth pressure for normally consolidated soil.

$$
\begin{aligned}
& K_{0}=1-\sin \phi^{\prime} \\
& K_{0, O C}=K_{0, N C}(O C R)^{\sin \phi^{\prime}}
\end{aligned}
$$

\subsection{Analysis Stages}

This numerical study employs construction stages, starting from the construction of the retaining wall, the construction of the ground anchors, to the excavation at the intended depth. Excavation stages are made uniform by setting each excavation stage at every $2 \mathrm{~m}$ until the desired depth. One of the variations in this study is excavation depth, hence the total number of analysis stages at each depth variation varies. However, those depth variations have a similarity in retaining wall construction before excavation and ground anchor construction after the excavation reaches $2 \mathrm{~m}$ in depth. All analysis stages of the excavation are described in Table 7.

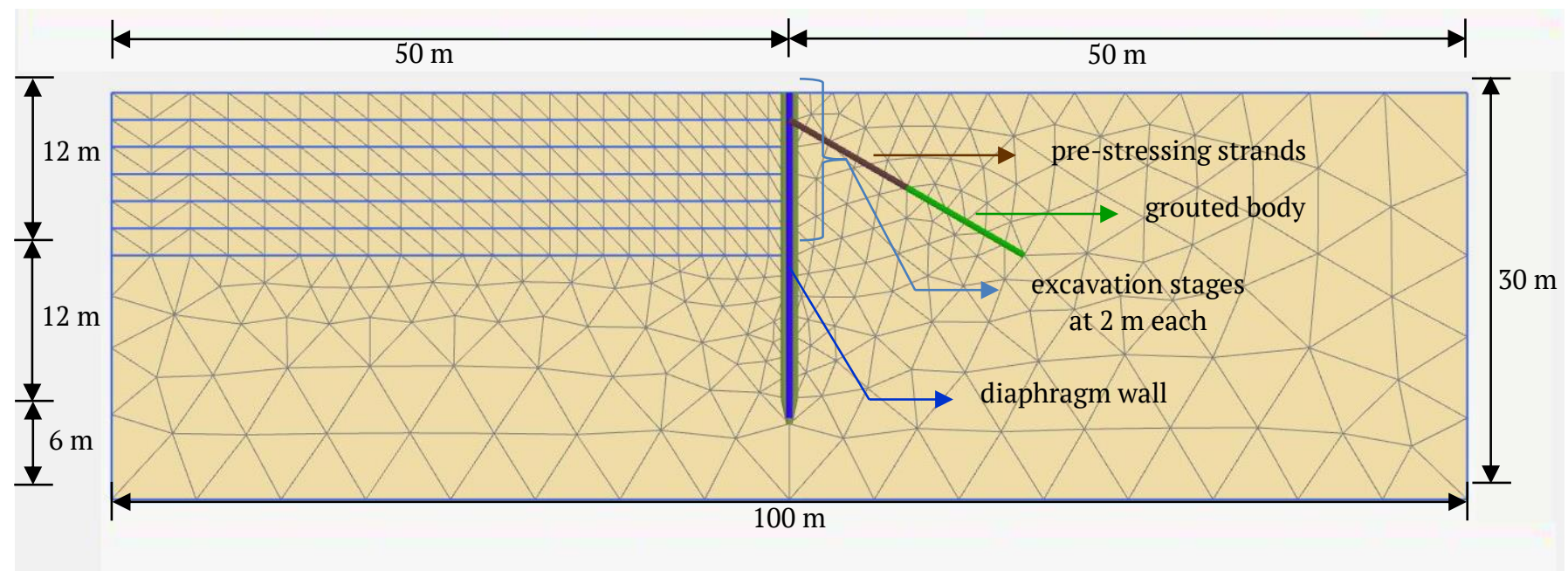

Figure $3.12 \mathrm{~m}, H_{p} / H_{e}=1.0$ excavation model meshes in Plaxis 2D

Table 7. Analysis phases of excavation numerical model

\begin{tabular}{llll}
\hline No. & 5 m excavation model & 8 m excavation model & $12 \mathrm{~m}$ excavation model \\
\hline 1 & Retaining wall construction & Retaining wall construction & Retaining wall construction \\
2 & Excavation to $2 \mathrm{~m}$ depth & Excavation to $2 \mathrm{~m}$ depth & Excavation to $2 \mathrm{~m}$ depth \\
3 & Ground anchor construction & Ground anchor construction & Ground anchor construction \\
4 & Excavation to $4 \mathrm{~m}$ depth & Excavation to $4 \mathrm{~m}$ depth & Excavation to $4 \mathrm{~m}$ depth \\
5 & Excavation to $5 \mathrm{~m}$ depth & Excavation to $6 \mathrm{~m}$ depth & Excavation to $6 \mathrm{~m}$ depth \\
6 & - & Excavation to $8 \mathrm{~m}$ depth & Excavation to $8 \mathrm{~m}$ depth \\
7 & - & - & Excavation to $10 \mathrm{~m}$ depth \\
8 & - & - & Excavation to $12 \mathrm{~m} \mathrm{depth}$ \\
\hline
\end{tabular}




\section{RESULTS AND DISCUSSION}

\subsection{Effect of Excavation Depth to the Wall Deflection}

The deflection of the excavated wall from the finite element method analysis is illustrated in the wall deflection vs wall depth curve. To provide an overview of the deflection pattern, the author shows an example of the excavation deflection pattern at $\phi^{\prime}$ of $28^{\circ}$ and $H_{p} / H_{e}$ of 0.75 , as shown in Figure 4. Each of the three figures represents excavation depth variation. show wall deflection curves for excavation with a depth of $5 \mathrm{~m}, 8 \mathrm{~m}$, and $12 \mathrm{~m}$ respectively. Each of excavation depth variations consists of three curves categorized by wall embedment length ratio, $H_{p} / H_{e}$, namely (a) 0.5 , (b) 0.75 , and (c) 1.0 . All deflection curves are drawn by adhering to the following convention: the positive side represents the excavated side, while the negative side represents the retained side of the wall.

Figure 4 shows the wall deflection curve for $5 \mathrm{~m}$ deep excavation in loose sand with variations on $H_{p} / H_{e}$ of $0.5,0.75$, and 1.0. The wall deflection shows a linear trend. At $F$ of $300 \mathrm{kN} / \mathrm{m}$ and 600 $\mathrm{kN} / \mathrm{m}$, the deflection on the top of the wall is pushing towards the retained side, denoted by the negative deflection.

Based on the wall deflection curves in Figure 4, the wall deflection at deeper excavation is larger than the wall deflection in the shallower excavation. As shown in Figure 4(a), at $5 \mathrm{~m}$ excavation, $F$ ranged from 0 to $100 \mathrm{kN} / \mathrm{m}$ deflects towards the excavated side, while at $F$ of 300 and $600 \mathrm{kN} / \mathrm{m}$, the wall deflects towards the retained side. Based on the $8 \mathrm{~m}$ excavation curve in Figure 4(b), the wall tends to deflect towards the excavated side, then at 4-8.5 $\mathrm{m}$ depth deflects toward the retained side, but the deflection at the wall bottom is positive. The deflection curve of $12 \mathrm{~m}$ excavation in Figure 4(c) shows that the deflection has a nonlinear trend towards excavated side but with larger deflection than those at $5 \mathrm{~m}$ and $8 \mathrm{~m}$ excavation.

\subsection{Effect of Wall Embedment Length to the Wall Deflection}

In this section, the deflection curves displayed in Figure 5 are the curves of $5 \mathrm{~m}$ and $12 \mathrm{~m}$ excavation in loose sand at $\phi^{\prime}$ of $28^{\circ}$ and with the variation of wall embedment length in $H_{p} / H_{e}$ of $0.5,0.75$, and 1.0. Based on deflection curves shown in Figure 5, the wall deflections of excavations with longer wall embedment length are smaller than those with shallower wall embedment length. In addition, the pre-stress force applied to the ground anchor helps to reduce the maximum deflection of the wall.

\subsection{Correlation of Retaining Wall Deflection and Normalized Pre-stress Force}

In this section, there are two parameters used, namely $\delta_{\mathrm{h}_{-} \text {top }} / H_{e}$ and $F /\left(s \cdot p_{a}\right) . \quad \delta_{\mathrm{h}_{-} \text {top }} / H_{e}$ is wall deflection at the wall top ( $\left.\delta_{\mathrm{h}_{-} \text {top }}\right)$ and excavation depth $\left(H_{e}\right)$ ratio, while $F /\left(s \cdot p_{a}\right)$ is the pre-stress force $(F)$ and ground anchor horizontal spacing $(s)$ ratio, and $p_{a}$, the atmospheric pressure of $101.325 \mathrm{kN} / \mathrm{m}^{2}$, is used to correct the $F /\left(s \cdot p_{a}\right)$ ratio so the ratio is unitless. The sign convention used for $\delta_{\text {h_top }} / H_{e}$ is positive for deflection towards the excavated side and negative for deflection towards the retained side.

Figure 6 shows the relationship between the deflection on the top of the retaining wall and pre-stress force for excavation with the depth of $5 \mathrm{~m}, 8 \mathrm{~m}$, and $12 \mathrm{~m}$, respectively. Based on Figure 6 , the $\delta_{\mathrm{h}_{-} \text {top }} / H_{e}$ tends to decrease at the $F /\left(s \cdot p_{a}\right)$ increase. Almost all excavation depth and sand density variations have negative $\delta_{\mathrm{h}_{-} \text {top }} / H_{e}$ values at larger $F /\left(s \cdot p_{a}\right)$ value, except the $12 \mathrm{~m}$ excavation at $\phi^{\prime}$ of $28^{\circ}$ shown in Figure 6(c) due to boundary effect in finite element model. The $\delta_{\mathrm{h}_{\_} \text {top }}$ in $12 \mathrm{~m}$ deep excavation at $\phi^{\prime}$ of $28^{\circ}$ Figure 6(c) shows a large positive value at 600 $\mathrm{kN} / \mathrm{m}$ pre-stress, ranged from $0.43 \% H_{e}$ to $0.59 \%$ $H_{e}$. The value range is a sign that a pre-stress force larger than $600 \mathrm{kN} / \mathrm{m}$ is needed to nullify the deflection on the wall top in loose sand, or more than one ground anchor is needed to minimize $\delta_{\mathrm{h}_{-} \text {top }}$. The increase in excavation depth 
has an impact on the reduction of $\delta_{\mathrm{h}_{-} \text {top }}$ by using pre-stress by at least $0.041 \% H_{e}$ at $5 \mathrm{~m}$ excavation, $0.024 \% H_{e}$ at $8 \mathrm{~m}$ excavation, and $0.005 \% H_{e}$ at 12 $\mathrm{m}$ excavation for $50 \mathrm{kN} / \mathrm{m}$ pre-stress increase. The data indicate that wall deflection reduction by applying pre-stress has less influence in the deeper excavation.

Based on the deflection curves in Figure 6, increasing the embedment length of the soil retaining wall by $0.25 H_{e}$ reduces $\delta_{\mathrm{h}_{-} \text {top }}$ by $0.007-$ $0.095 \% H_{e}, 0.011-0.046 \% H_{e}$, and $0.002-0.026 \%$ $H_{e}$ for $\phi^{\prime}$ of $28^{\circ}, 33^{\circ}$, and $38^{\circ}$ respectively. One example is taken from $8 \mathrm{~m}$ excavation at $\phi^{\prime}$ of $28^{\circ}$ in Figure 6(b) at $\mathrm{F}$ of $100 \mathrm{kN} / \mathrm{m}$. The $\delta_{\mathrm{h}_{-} \text {top }} / H_{e}$ at embedment length of $0.5 \mathrm{H}_{e}, 0.75 \mathrm{H}_{e}$, and $1.0 \mathrm{H}_{e}$ are $0.22 \%, 0.16 \%$, and $0.13 \%$, respectively. Therefore, it can be inferred that using the large embedment length affects less on wall deflection in denser sand than those in loose sand, since high friction angle of sand, along with the normal effective stress, contribute to the high shear strength of sand.

The increase in pre-stress force is able to reduce the deflection of the upper end of the wall by $0.005 \%-0.083 \% H_{e}$ per $50 \mathrm{kN} / \mathrm{m}$ pre-stressing increase. However, the pre-stressing influence on reducing wall deflection decreases as the prestress force reaches high $F$ magnitude (for example from $300 \mathrm{kN} / \mathrm{m}$ to $600 \mathrm{kN} / \mathrm{m}$ ) than the increase of pre-stress at a low $F$ magnitude (for example from 0 to $50 \mathrm{kN} / \mathrm{m}$ ). Even in $5 \mathrm{~m}$ excavations, pre-stress at $300 \mathrm{kN} / \mathrm{m}$ and above results in wall deflections towards the retained side. Therefore, it is not recommended to use a pre-stress force greater than $300 \mathrm{kN} / \mathrm{m}$ for any ground anchors excavated at a depth ranging from 5 to $12 \mathrm{~m}$.

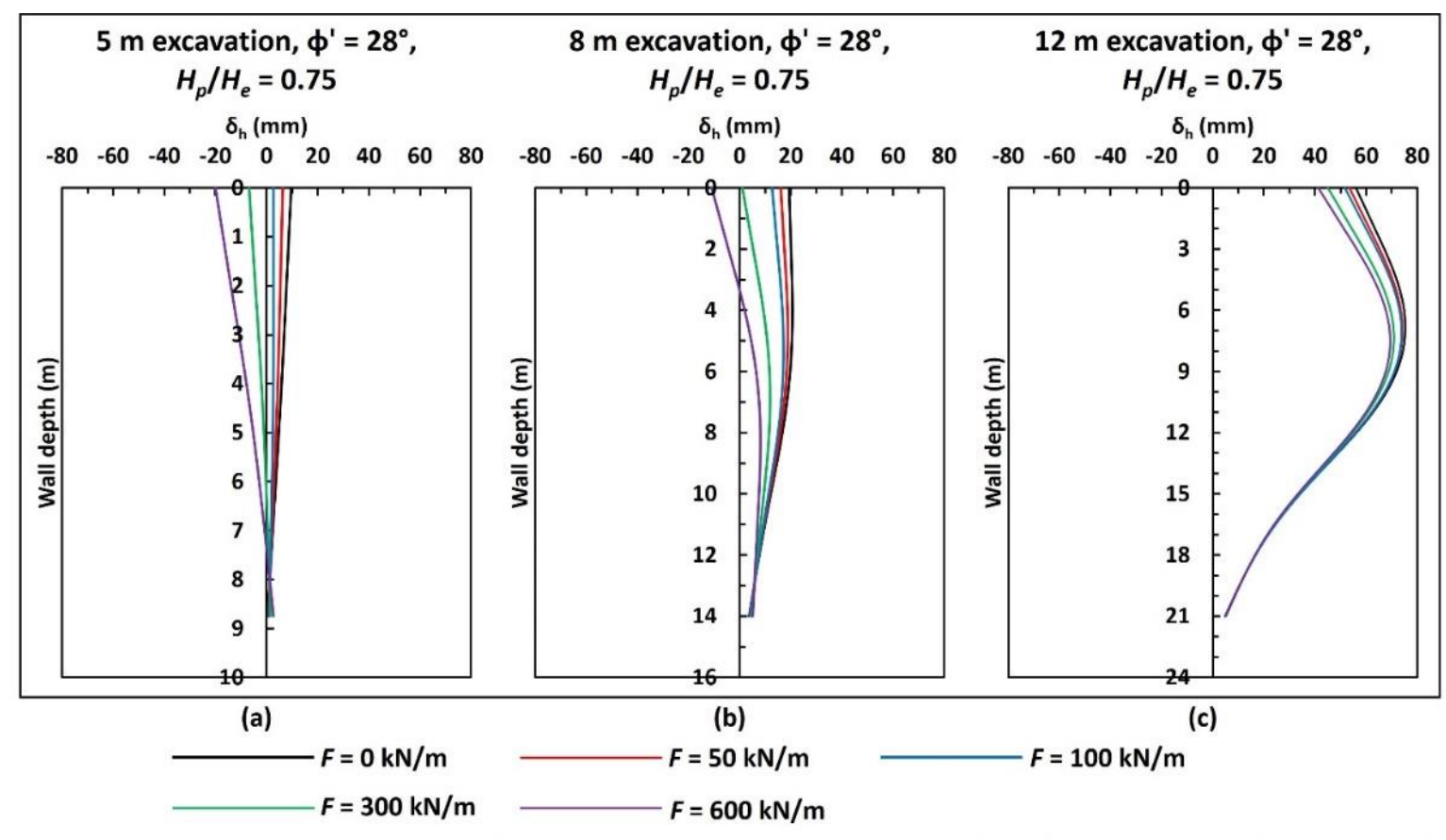

$F$ denotes pre-stress anchor force; $H_{e}$ denotes excavation depth; $H_{p}$ denotes wall embedment length; $\delta_{\mathrm{h}}$ denotes wall deflection

Figure 4. Wall deflection curves for excavations with $\phi^{\prime}=28^{\circ}$ and $H_{p} / H_{e}=0.75$ at excavation depth variations of (a) $5 \mathrm{~m}$, (b) $8 \mathrm{~m}$, and (c) $12 \mathrm{~m}$. 


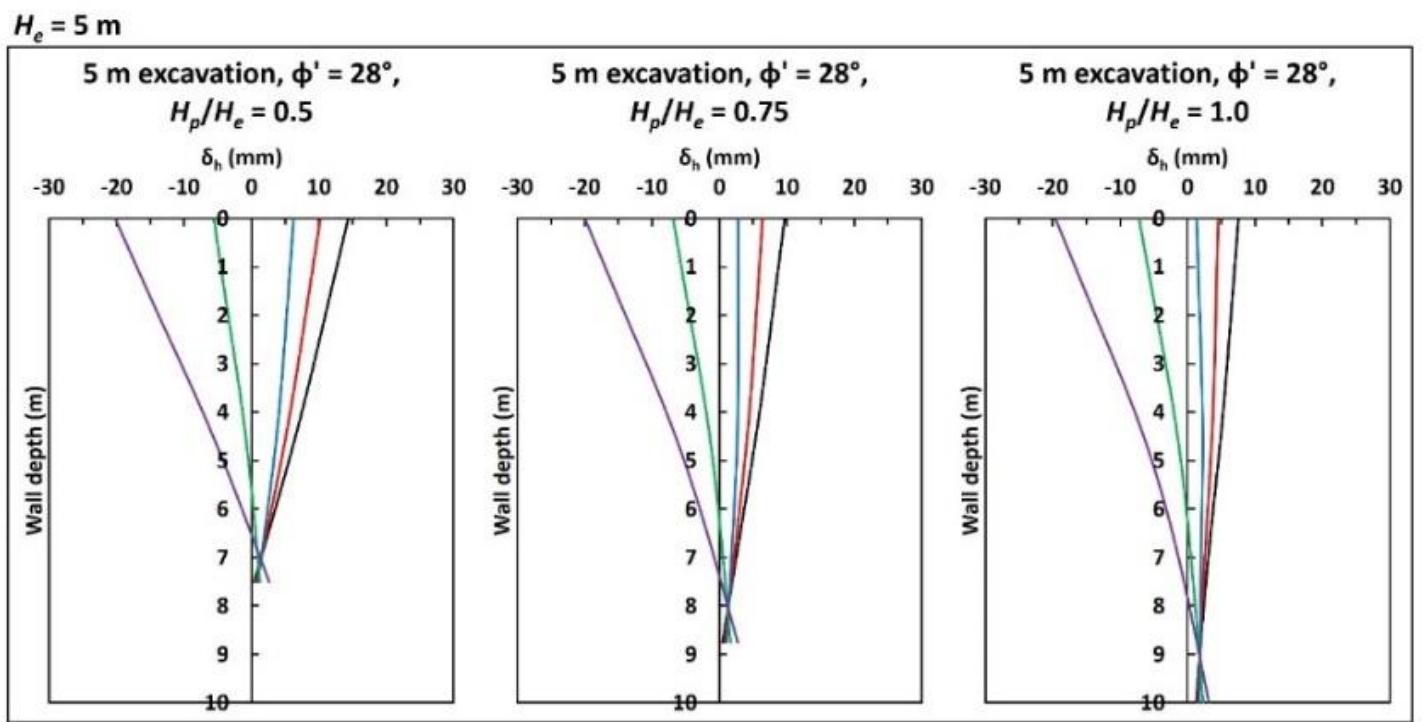

(a)

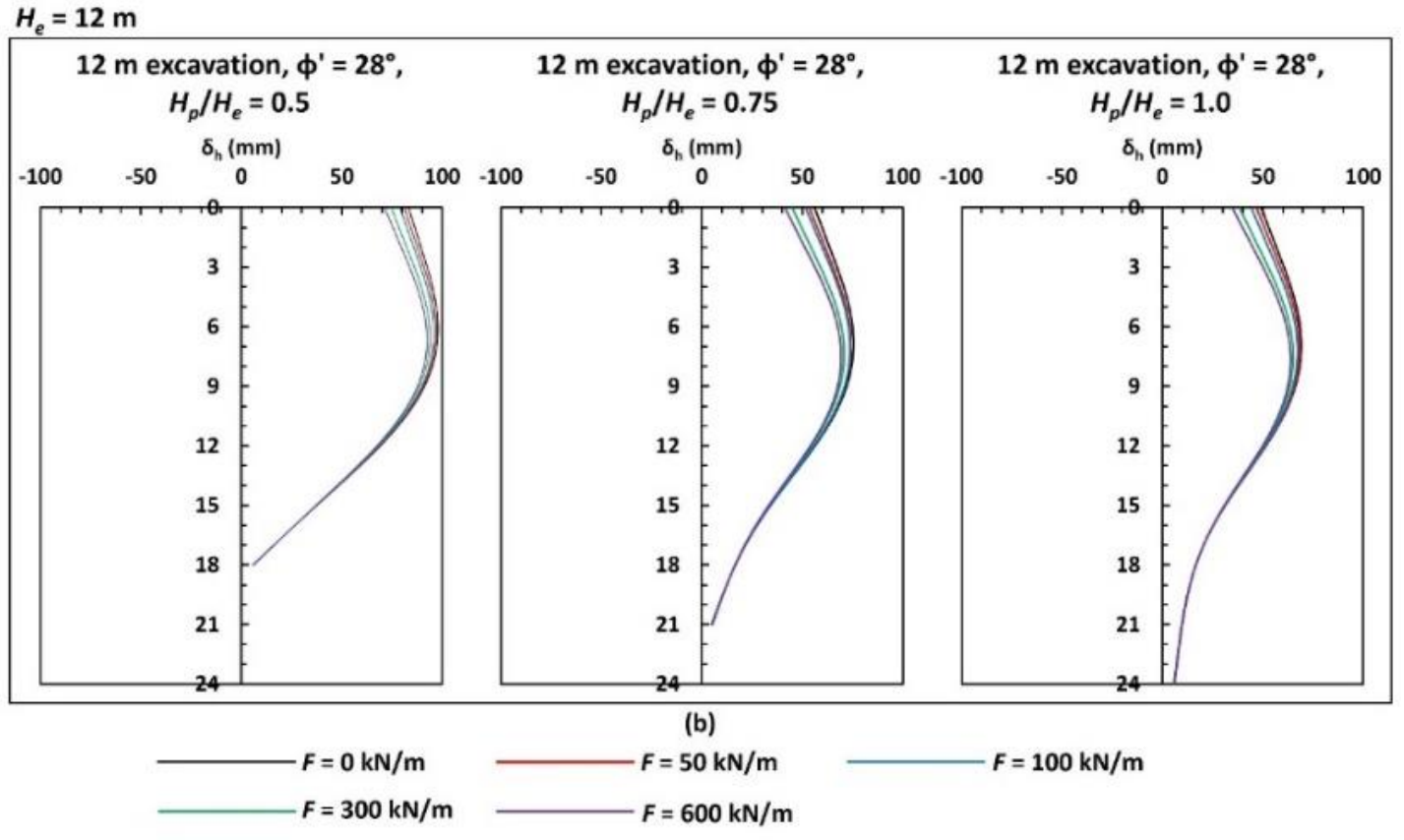

$F$ denotes pre-stress anchor force; $H_{e}$ denotes excavation depth; $H_{p}$ denotes wall embedment length; $\delta_{h}$ denotes wall deflection

Figure 5. Wall deflection curves for excavation with $\phi^{\prime}$ at $28^{\circ}, H_{p} / H_{e}$ variations of $0.5,0.75$, and 1.0 , and $H_{e}$ of (a) $5 \mathrm{~m}$ and (b) $12 \mathrm{~m}$. 


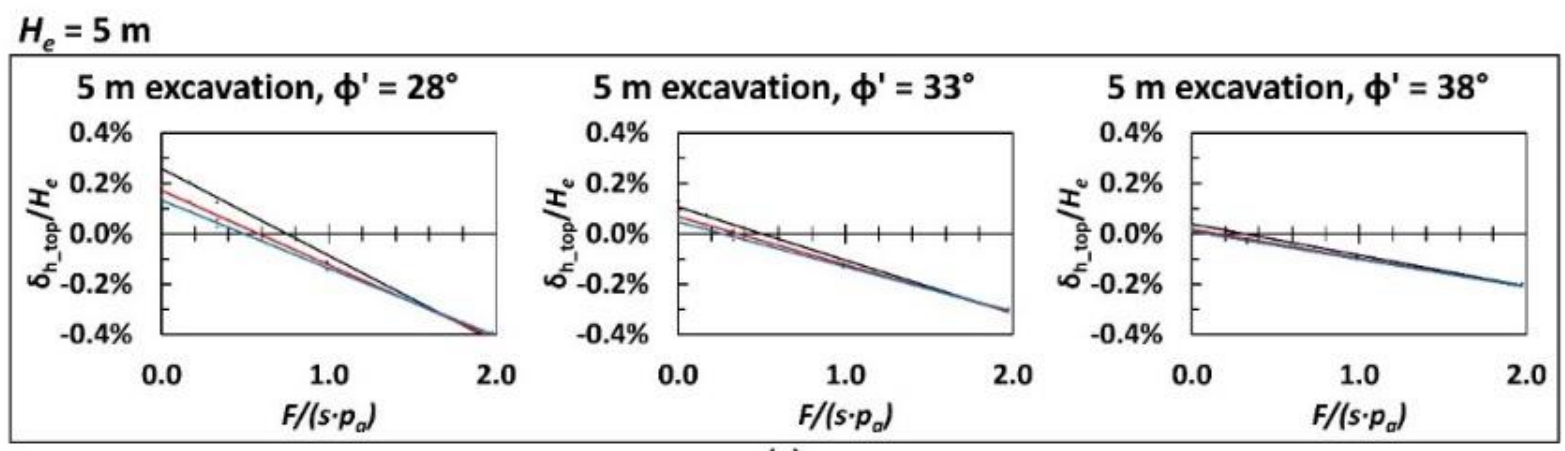

(a)
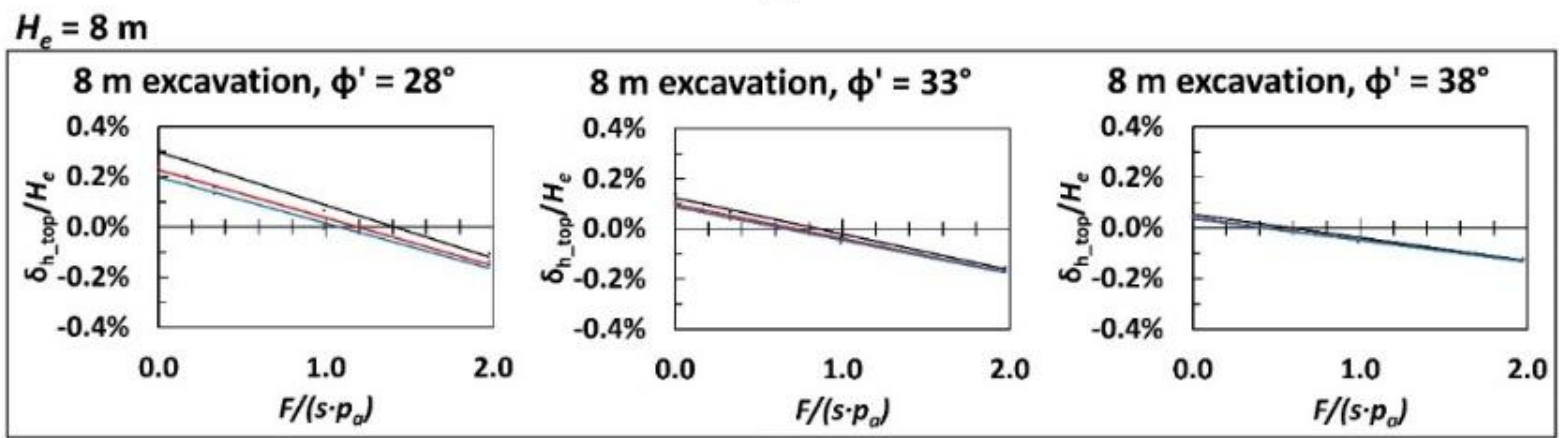

(b)
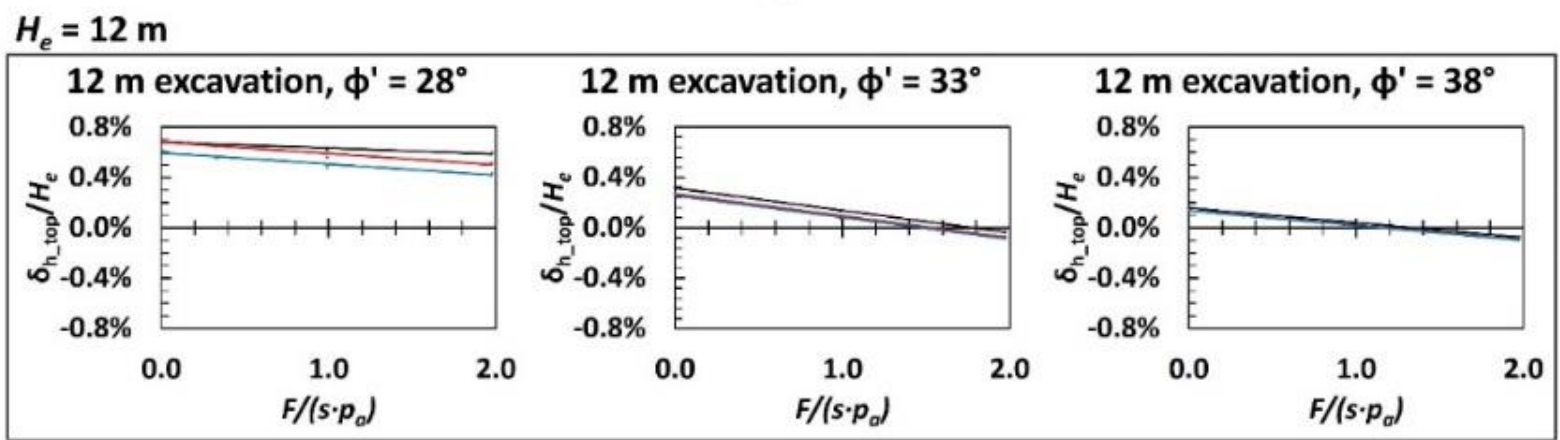

(c)

$\longrightarrow \mathrm{H}_{p}=0.5 \mathrm{H}_{e} \longrightarrow \mathrm{H}_{p}=0.75 \mathrm{H}_{e} \longrightarrow \mathrm{H}_{p}=1.0 \mathrm{H}_{e}$

$\delta_{h \_t o p}$ denotes wall top deflection; $F$ denotes the pre-stress anchor force, $s$ denotes the anchor horizontal spacing, $p_{a}$ denotes atmospheric pressure at $101.325 \mathrm{kPa}$.

Figure 6. Chart for predicting anchored wall deflection for (a) $H_{e}=5 \mathrm{~m}$, (b) $H_{e}=8 \mathrm{~m}$, (c) $H_{e}=12 \mathrm{~m}$.

\section{CONCLUSIONS AND RECOMMENDATIONS}

This parametric study showed that pre-stress forces play a role in reducing wall deflection, with varying effects on the depth of excavation, the length of immersion, and different angles of soil shear. The reduction in deflection that occurs is $0.005 \%-0.083 \% H_{e}$ for each increase in the pre-stress force of $50 \mathrm{kN} / \mathrm{m}$. However, the pre-stressing effect in reducing wall deflection is less significant at the sand with higher density, caused by the higher strength of soil at a larger friction angle. The length of immersion of the retaining wall, together with pre-stressing the soil anchors, significantly reduces wall deflection. The addition of a $H_{p}$ of $0.25 H_{e}$ can reduce deflection by $0.002-0.095 \% H_{e}$. This study can be further developed by comparing the analysis results with field observations and varying finite element model mesh size, groundwater level ground anchor spacing, and soil stratification.

\section{DISCLAIMER}

The authors declare no conflict of interest.

AVAILABILITY OF DATA AND MATERIALS

All data are available from the author. 


\section{ACKNOWLEDGMENTS}

The authors thank the Universitas Katolik Parahyangan for allowing the usage of their PLAXIS 2D software.

\section{REFERENCES}

Birid, K., Maitra, S., Choudhury, D., Beniwal, M., 2020. Nearshore deep excavation and associated problems in cohesionless soil. Proceedings of the Institution of Civil Engineers - Forensic Engineering, 173(2), 54-61.

Chen, J.R., 2004. Axial Behavior of Drilled Shafts in Gravelly Soils, New York: Ph.D. Dissertation. Cornell University.

Duncan, J., and Chang, C., 1970. Nonlinear Analysis of Stress and Strain in Soils. Journal of the Soil Mechanics and Foundations Division, 96(5), 1629-1653.

Elbaz, K., Shen, S.L., Tan, Y., Cheng, W.C., 2018. Investigation into Performance of Deep Excavation in Sand Covered Karst: A Case Report, Soils and Foundations, 8(4), 1042-1058.

Elhakim, A.F. and Tahsin, A., 2011. Post Tensioning Effects on Anchored Diaphragm Walls in Sand. Hong Kong, The 14th Asian Regional Conference on Soil Mechanics and Geotechnical Engineering.

Fuentes, R., Pillai, A., Ferreira, P., 2018. Lessons learnt from a deep excavation for future application of the observational method. Journal of Rock Mechanics and Geotechnical Engineering, 10(3), 468-485.

Gibbs, H.J. and Holtz, W.G., 1957. Research on Determining the Density of Sands by Spoon Penetration Testing. London, Proc. 4th Inter. Conf. Soil Mech. Found. Eng., I, 35.

Gouw, T.L., 2014. Common Mistakes on the Application of Plaxis 2D in Analyzing Excavation Problems. International Journal of Applied Engineering Research, 9(21), 8291-8311.

Han, J.Y., Zhao, W., Chen, Y., Jia, P.J., and Guan, Y.P., 2017. Design Analysis and Observed Performance of a Tieback Anchored Pile Wall in
Sand, Mathematical Problems in Engineering, 2017, $1-23$.

Hatanaka, M. and Uchida, A., 1996. Empirical Correlation between Penetration Resistance and Internal Friction Angle of Sandy Soils. Soils and Foundations, 36(4), 1-9.

Hsiung, B.C.B., Yang, K.H., Aila, W., Hung, C., 2016. Three-Dimensional Effects of a Deep Excavation on Wall Deflections in Loose to Medium Dense Sands. Computers and Geotechnics, 80, 138-151.

Jaky, J., 1944. The Coefficient of Earth Pressure at Rest, Journal of the Society of Hungarian Architects and Engineers (in Hungarian), 8(22), 355-358.

Janbu, N., 1963. Soil Compressibility as Determined by Oedometer and Triaxial Tests. Wiesbaden, European Conf. Soil Mech. Found. Eng. ECSMFE, 1, 19-25, 1963.

Khoiri, M. and Ou, C.Y., 2013. Evaluation of Deformation Parameter for Deep Excavation in Sand Through Case Histories, Computers and Geotechnics, 47, 57-67.

Kondner, R.L. and Zelasko, J.S., 1963. A Hyperbolic Stress Strain Formulation for Sands. Brazil, Proc. 2nd Pan. Am. ICOSFE, 1, 289-394.

Lim, A., Ou, C.Y., and Hsieh, P.G., 2010. Evaluation of Clay Constitutive Models for Analysis of Deep Excavation under Undrained Conditions. Journal of GeoEngineering, 5(1), 9-20.

Mayne, P.W. and Kulhawy, F.H., 1982. K0-OCR Relationships in Soil. Journal of Geotechnical Engineering, 108, 851-872.

Nikolinakou, M.A., Whittle, A.J., Savidis, S., and Schran, U., 2011. Prediction and Interpretation of the Performance of a Deep Excavation in Berlin Sand. Journal of Geotechnical and Geoenvironmental Engineering, 137(11), 10471061.

Schanz, T., Vermeer, P.A., and Bonnier, P.G., 1999. The hardening soil model: formulation and verification. Amsterdam, Beyond 2000 in 
Computational Geotechnics: Ten Years of PLAXIS International, 281-296.

St. Clair, M.J., 2017. Numerical Analysis of the Effect of Pre-Stress on Excavation Supports, Taipei: Master Thesis Report. Department of Civil Engineering. National Taiwan University of Science and Technology.

Teo, P.L. and Wong, K.S., 2012. Application of the Hardening Soil Model in Deep Excavation Analysis. The IES Journal Part A: Civil \& Structural Engineering, 5(3), 152-165.
Terzaghi, K. and Peck, R.B., 1948. Soil Mechanics in Engineering Practice. New York: John Wiley.

Von Soos, P., 1990. Properties of soil and rock (in German). Grundbautaschenbuch Part 4. Berlin: Ernst \& Sohn.

Wang, X.Q., Zhen, T.Y., and Liao, Z.Y., 2019. Deformation Characteristics of Deep Excavation for an Interchange Station Based on the Model of Hardening Soil. Nanjing, International Conference on Civil and Hydraulic Engineering. 
[This page is intentionally left blank] 